\title{
Influence of the Addition of Silica Nanoparticles on the Compressive Strength of Cement Slurries under Elevated Temperature Condition
}

\author{
Anna Pikłowska ${ }^{1}$, Jan Ziaja ${ }^{1}$ (D) and Marcin Kremieniewski ${ }^{2, *(D)}$ \\ 1 Department of Drilling and Geoengineering, Faculty of Drilling, Oil and Gas, AGH University of Science and \\ Technology, 30-059 Kraków, Poland; annapiklowska@gmail.com (A.P.); ziaja@agh.edu.pl (J.Z.) \\ 2 Oil and Gas Institute-National Research Institute, 31-503 Krakow, Poland \\ * Correspondence: kremieniewski@inig.pl
}

check for

updates

Citation: Pikłowska, A.; Ziaja, J.; Kremieniewski, M. Influence of the Addition of Silica Nanoparticles on the Compressive Strength of Cement Slurries under Elevated Temperature Condition. Energies 2021, 14, 5493 https://doi.org/10.3390/en14175493

Academic Editors: Pål

Østebø Andersen and

George Avgouropoulos

Received: 30 July 2021

Accepted: 28 August 2021

Published: 3 September 2021

Publisher's Note: MDPI stays neutral with regard to jurisdictional claims in published maps and institutional affiliations.

Copyright: (C) 2021 by the authors. Licensee MDPI, Basel, Switzerland. This article is an open access article distributed under the terms and conditions of the Creative Commons Attribution (CC BY) license (https:/ / creativecommons.org/licenses/by/ $4.0 /)$.

\begin{abstract}
Drilling ever deeper, and thus in increasingly difficult conditions, is associated with restrictive requirements that must be met by cement slurries. This implies the need to use advanced, innovative measures that will significantly improve the performance parameters of the cement slurry and cement stone. Due to its unique properties, an admixture of nanosilica improves the properties of the cement stone and allows for appropriate zone insulation. The article presents the results of strength tests of cement stone samples with the addition of silica nanoparticles deposited in an environment of increased temperature of $90{ }^{\circ} \mathrm{C}$. In all three cases of modification with an admixture of nanosilica (type 1, 2 and 3, concentration $0.5 \%, 1 \%$ and $5 \%$ ), the cement stone shows an improvement in mechanical properties, which is manifested by an increase in compressive strength. The most homogeneous results of strength measurements are for cement slurries with an admixture of type 3 nanosilica (the highest average strength: $132-149 \%$ in relation to the base sample). They show the smallest stretch marks and deviations from the average. The highest average increase in strength is for the sample with the addition of $1 \%$ nanosilica (on average $124 \%$ in relation to the base sample). This amount causes the greatest increase in strength with no significant deterioration of rheological parameters.
\end{abstract}

Keywords: well cementing; improved borehole sealing; nanosilica; cement stone; cement slurry; mechanical parameters

\section{Introduction}

In the petroleum industry, the purpose of cementing in boreholes is primarily to create a resistant and durable barrier against fluid migration. Migration takes place between zones in rock formations. It is important to obtain a permanent connection of the cement sheath in the annular space between the borehole wall and the casing column. Additionally, the cement stabilizes the casing and protects it against corrosion and shock loads. The task of the cement sheath is also to seal the mud escape zone and other sections of the hole where drilling is difficult. Cement used in drilling will hydrate under different conditions than the cement used in conventional construction. The high temperature and pressure at great depths are a major obstacle here. The presence of highly mineralized reservoir brines and hydrogen sulfide, which adversely affect the durability of the cement sheath, is also important [1,2]. The increase in global energy consumption and the growing demand for fossil fuels as the dominant energy source significantly accelerated the development of new technologies in hydrocarbon production [3,4]. Drilling deeper and deeper creates more and more difficult conditions for the cement slurry and increases the requirements $[5,6]$. Cement slurries must be able to cope with them, therefore it implies the need to use advanced, innovative measures that will improve the functional parameters of cement slurry and cement stone [7-10]. Such activities allow for obtaining appropriate zone insulation. 
For this purpose, the use of nanotechnology is very beneficial, which has become one of the paths of development and progress in recent years [11,12]. It allows you to design, manufacture, study and apply structures at the level of single atoms and particles with nanometric sizes-in which at least one of the size dimensions is smaller than $100 \mathrm{~nm}$ [13]. Thanks to the rapid development of this field, a new class of materials, such as nanoparticles, is widely studied in order to provide simpler and more economical hydrocarbon exploration and production processes, especially in difficult reservoir conditions [14-16]. In the last dozen or so years, huge efforts have been made to develop methods of producing nanometric-sized materials. Nanosized particles can be prepared by physical, chemical or biological methods, depending on the nature of the materials and the contribution of chemical reactions [17]. The synthesis of nanoparticles can be classified as either "top-down" or "bottom-up". In a synthetic top-down method, nanoparticles are typically made by comminuting with a variety of physical and/or chemical treatments. There are mechanical milling, ball milling, chemical etching, thermal ablation, laser ablation, explosion and spraying. In the bottom-up approach, nanoparticles are formed by smaller entities such as atoms, molecules, and smaller particles as building blocks that are combined to form the final product. Typically, this method relies on chemical or biological mechanisms. Examples are chemical or electrochemical precipitation, vapor deposition, atomic or molecular condensation, sol-gel processes, spray pyrolysis, laser pyrolysis, aerosol processes, and chemical or biological reduction. Due to their large surface area, high aspect ratio, small size, low density, large surface area and interesting physicochemical properties, they have a strong influence on the mechanical properties of cement materials $[18,19]$. Research on the use of nanomaterials as additives to cement slurries began relatively recently [20]. The literature [11,21-23] provides examples of the use of nanoparticles as well as nano- $\mathrm{SiO}_{2}$ and nano- $\mathrm{Fe}_{2} \mathrm{O}_{3}$ additives improving the strength parameters of the cement matrix. In addition to improving strength, the addition of nano- $\mathrm{Fe}_{2} \mathrm{O}_{3}$ improves the ability to monitor stresses in the cement stone [24-26]. Increasingly, scientists are also using less popular nanoxides, such as zinc and titanium nanoxides [21,26-28]. Some authors also conducted research on the influence of carbon nanotubes on the mechanical parameters of the hardened cement slurry, however, the research in this area is ambiguous [8].

\section{Nanosilica in Cement Slurries}

One of the important additives in cement is silica, which is used in a certain amount to counteract the loss of strength. The use of nanosilica in cement resulting from the Stober method (a variant of the sol-gel method) improves the properties of hardened cement. Due to the extremely small size, high sphericity and relatively high quality, nanoparticles are preferred because their abrasive action is negligible with a lower impact of kinetic energy [1,9]. When nanosilica is used, the mechanism of its action is multifaceted. First of all, the addition of nanosilica increases the efficiency of C-S-H gel formation by promoting pozzolanic reactions. It influences the improvement of the microfilling effect of the cement matrix space. Silica nanoparticles act as nucleation sites for hydration products, and due to their high surface energy, cement hydration products are deposited on them. On the nano$\mathrm{SiO}_{2}$ surface, the hydration products grow into conglomerates containing nanoparticles as nuclei. The addition of nanosilica controls crystallization, limiting the amount of formation of large portlandite crystals. The synergistic effect of all these mechanisms results in the formation of a compact, durable and impermeable microstructure $[18,19,28]$. With the right composition, a higher packing density results in lower water requirements for the mixture and contributes to increased strength due to reduced capillary porosity (Figure 1). 


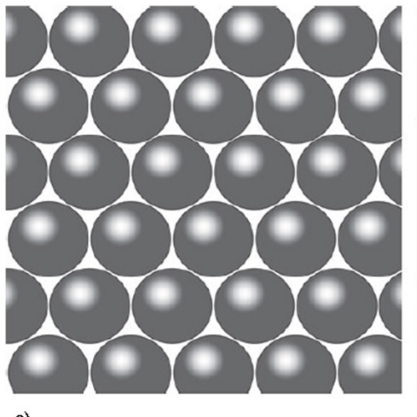

a)

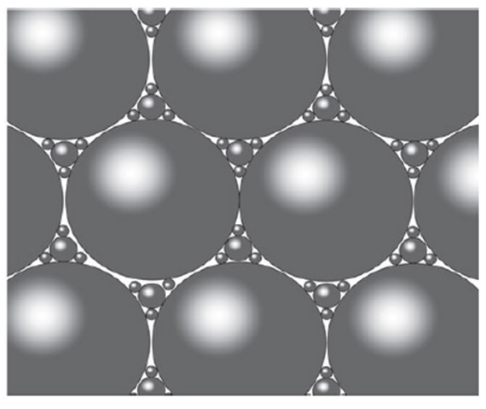

b)

Figure 1. (a) Packing density of a single size system. (b) Increased packing density of a system using an additive with different particle sizes Reprinted with permission from ref. [19]. Copyright 2013 Woodhead Publishing: Sawston, UK.

The nanoparticles have a large specific surface area, thus ensuring high chemical reactivity $[29,30]$. As a result, the nano- $\mathrm{SiO}_{2}$ present in the cement slurry additionally supports and accelerates the hydration process (Figure 2) [31]. Therefore, it seems advisable to add nanosilica particles to cement mixtures in order to obtain a better quality cement slurry $[32,33]$.

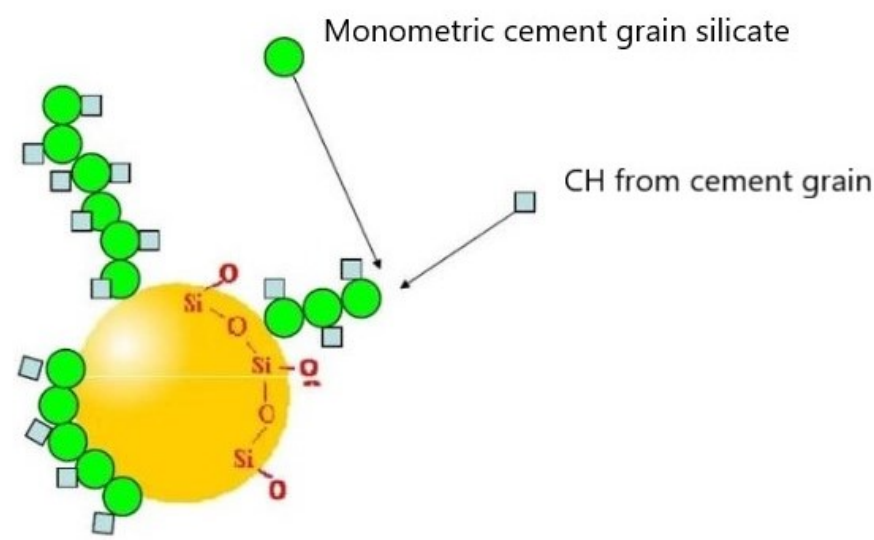

Figure 2. Mechanism of action of nanosilica. Monomeric silicates dissolved from the clinker phases are attracted by colloidal silica. The formed "silicate polymer" is stabilized with calcium hydroxide [manufacturer's materials, www.akzonobel.com (accessed on 6 March 2021)].

Based on the research, it is stated that the smaller the size of nanosilica particles, and therefore the larger the specific surface area, the higher the compressive strength of the tested samples [34,35]. However, the analysis of the results of research on nanosilica shows large discrepancies in the results. The reasons for these discrepancies are the differences in the methods and conditions under which the experiments are conducted. The molar ratio of the reactants, the type of silica precursor, the shape (nanospheres, fibers) and the type of nanoparticles, as well as the duration of the reaction in the sol-gel method and the degree of particle dispersion in the cement matrix are important. An important issue is the stability of the obtained mixtures due to the content of nanoparticles, as it depends to a degree on their size (Figure 3). Therefore, this article presents the effect of nanosilica admixtures of various sizes and concentrations on the mechanical properties of cement slurry matured under elevated temperature conditions. 


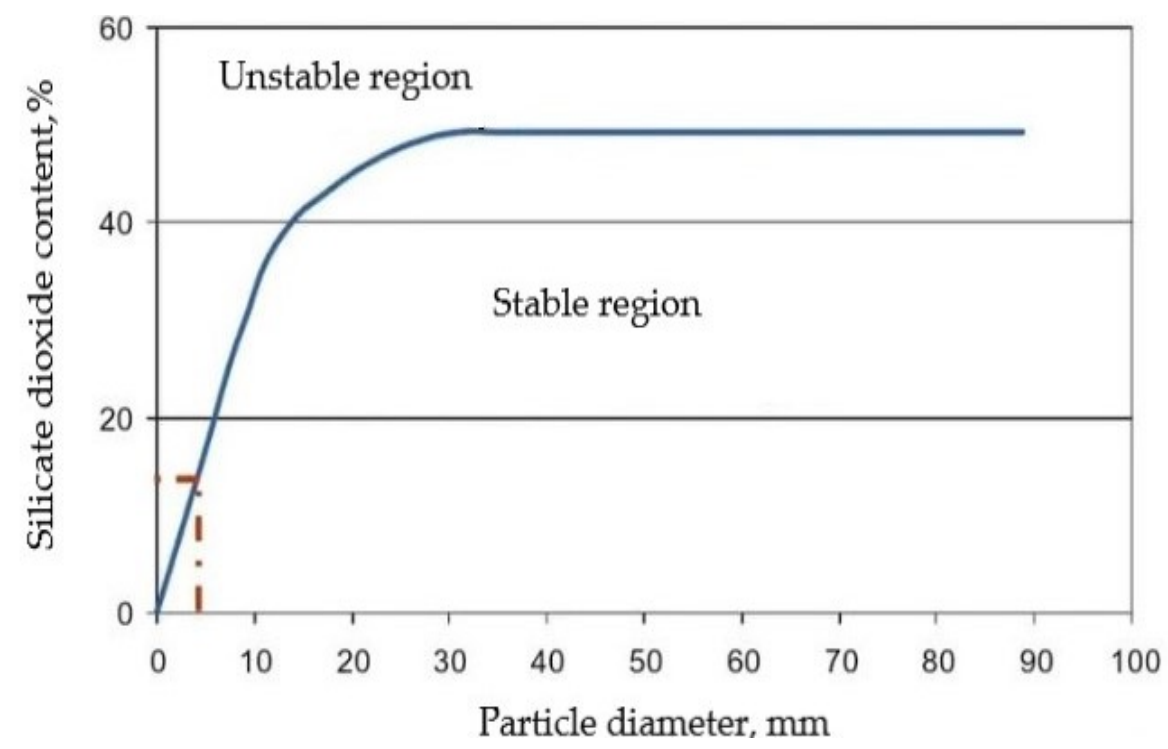

Figure 3. The dependence of the possible concentration of silica nanoparticles on the particle size. Reprinted with permission from ref. [9]. Copyright 2018 Egypt. J. Pet.

Patil and Deshpande [7] described the reports on the positive effect of nanosilica on the properties of cement slurries deposited in the borehole environment. They document a case where nanosilica was used in cementitious compositions to obtain high early strength. The addition of $0.2 \mathrm{gal} / \mathrm{sk}$ of nanosilica, the rate of strength development increased from 172 to $460 \mathrm{psi} / \mathrm{hr}$. The ultimate strength of cement composition was found to be three times that of the control and control plus microsilica. At the same time, Santra, Boul, and Pang [16] confirmed the positive effect of nanosilica, indicating that improvements in properties attributed to the incorporation of nanosilica into cement-based materials include increased early and final compressive strength. The nanosilica synthesized by Qalandari, Aghajanpour, and Khatibi [29] significantly increased the uniaxial compressive strength of the cement system (an increase of $16.59 \%$ with an addition of only $0.25 \%$ by weight). El-Gamal [2] claims that the addition of $1 \%$ nanosilica to oilwell cement leads to a marked increase in the compressive strength values at all ages of hydration, as compared to those of the neat paste (after 1, 3, 7 and 14 days). The positive effect of nanoparticles is also described by Debińska $[15,21]$. One of the groups of nanoparticles she studies is nanosilica. She notes that the slurry with the addition of nanosilica, tested at $90{ }^{\circ} \mathrm{C}$, was characterized by good rheological parameters, and the cement stone obtained from it was characterized by high values of early compressive strength (18 MPa after $24 \mathrm{~h}, 21 \mathrm{MPa}$ after $48 \mathrm{~h}$ ) and strength after 28 days reaching about $28 \mathrm{MPa}$. It is worth noting that the cement stones obtained from slurries with the addition of nanosilica were characterized by significantly higher values of compressive strength compared to the base slurry. Therefore, she concludes that these slurries can be the basis for the development of recipes for which high mechanical strength is required.

\section{Materials and Methods}

2.1. Materials

\subsubsection{Cement}

Class G German cement (Dyckerhoff) was used for the tests. The specific surface area (measured by the Blaine method) was $3462 \mathrm{~cm}^{2} / \mathrm{g}$. The alkali content was kept at $0.89 \%$, chlorides at $0.061 \%$ and sulfates at $3.23 \%$. The loss on ignition was $3.03 \%$, while the insoluble residue was $0.54 \%$. The stability of the volume was determined at the level of $0.44 \mathrm{~mm}$. 


\subsubsection{Silica Nanoparticles}

Three types of water dispersion of nanosilica particles were used for the tests. The additives differ in properties, mainly in the size of the particles.

Silica 1 is an alkaline, aqueous dispersion of colloidal silica that contains about $50 \%$ by weight solids. The silica dispersion is stabilized with sodium and the amorphous silica particles have a negative surface charge. $\mathrm{SiO}_{2}$ particles have a smooth, spherical shape and a wide size distribution, on average around $32 \mathrm{~nm}$. It is physically a white liquid, slightly more viscous than water.

Silica 2 is a transparent, aqueous suspension of silicon oxide nanopowder particles that contains $25 \%$ by weight solids. $\mathrm{SiO}_{2}$ particles have a spherical shape, particle size: $30 \mathrm{~nm}$ (Figure 4).

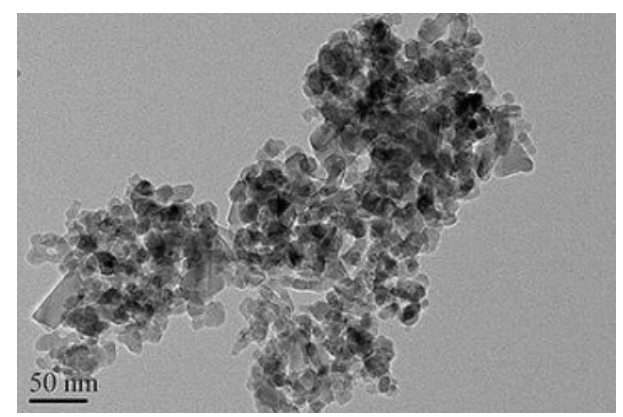

Figure 4. Type 2 nanosilica [manufacturer's materials, www.us-nano.com (accessed on 14 March 2021)].

Silica 3 is a transparent, aqueous suspension of silicon oxide nanopowder particles that contains $25 \%$ by weight solids. $\mathrm{SiO}_{2}$ particles have a spherical shape, particle size: 5-35 nm.

\subsection{Preparation of Samples}

In order to eliminate the influence of many variables on the result of the experiment, the water-cement ratio $(w / c)$ of all tested cement slurries was equal to 0.5 . The slurry was made by dosing the appropriate amount of tap water and cement. Before mixing them, additives regulating the technological parameters of the slurry were introduced into the mixing water, i.e., defoamer, fluidizing agent, delaying setting and regulating filtration. Selected types of nanosilica in concentrations $(0.5 \%, 1 \%, 5 \%)$ were introduced into the solution prepared in this way, followed by cement. The cement slurry prepared in this way was mixed for $30 \mathrm{~min}$ with a rotational speed of $160 \mathrm{rpm}$. The adopted mixing conditions corresponded to the slurry preparation technology in borehole conditions. Due to the form of nanosilica addition (water dispersion), the calculated amount of water resulting from the assumed $w / c$ ratio was reduced by appropriate values. For comparison, a reference cement slurry was also prepared (without the addition of silica). The cement slurry was poured into $4 \times 4 \times 4 \mathrm{~cm}$ cubic molds and placed in an autoclave at $90{ }^{\circ} \mathrm{C}$ and $80 \%$ humidity for $24 \mathrm{~h}$. Then, for the next seven days, the samples were placed in water at $90^{\circ} \mathrm{C}$ (Figure 5). Detailed methodology chart is in Table 1. Compressive strength tests were performed from samples seasoned in this way. 


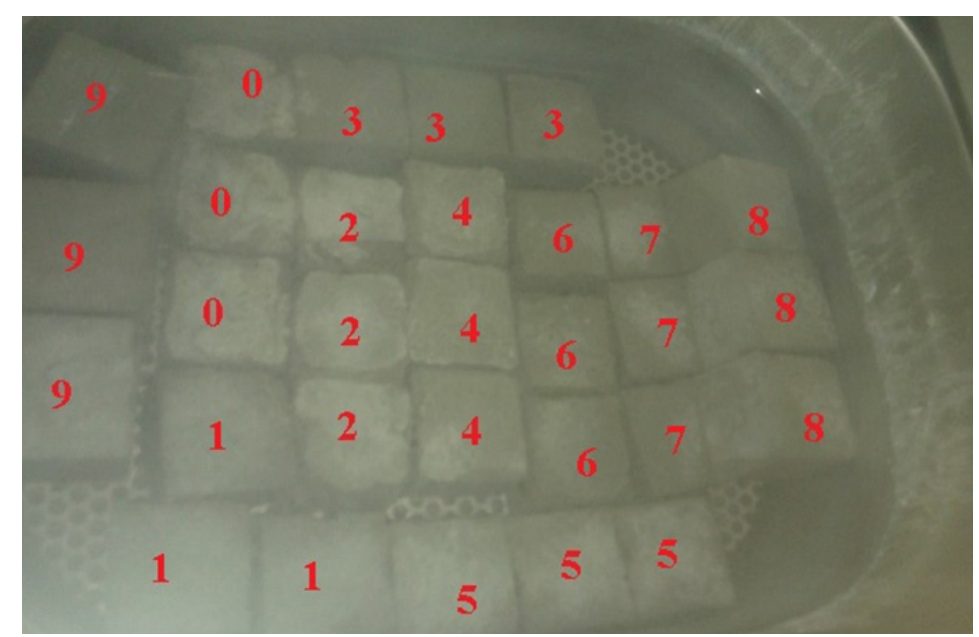

Figure 5. Autoclave samples (photo by the author).

Table 1. Detailed methodology chart.

\begin{tabular}{ccc}
\hline \multicolumn{2}{c}{$w / c$} & $\mathbf{0 . 5}$ \\
\hline \multicolumn{2}{c}{ Concentrations of nanosilica } & $0 \%, 0.5 \%, 1 \%, 5 \%$ \\
Conditions for first $24 \mathrm{~h}$ & humidity & $80 \%$ \\
& temperature & $90{ }^{\circ} \mathrm{C}$ \\
Conditions for first $24 \mathrm{~h}$ & humidity & $100 \%$ \\
& temperature & $90{ }^{\circ} \mathrm{C}$ \\
\hline
\end{tabular}

\subsection{Experimental Procedures}

The mechanical strength was determined using a testing machine (hydraulic press) model E183 PN 100 Matest. It was designed to determine the bending and compressive strength of cement stone. The test consists in measuring the crushing force needed to destroy the sample. The tested samples were loaded with a speed dependent on the expected compressive strength.

\section{Results and Discussion}

The results of the compressive strength measurements are presented in the table (Table 2) and the graph (Figure 6). Tables 3 and 4 present the statistical processing of the obtained results.

Table 2. Results of compressive strength of samples seasoned for 7 days (MPa).

\begin{tabular}{cccccc}
\hline System No. & Concentration of Nanosilica & Sample 1 & Sample 2 & Sample 3 & Average Value \\
\hline 0 & $0.0 \%$ & 22.8 & 24.31 & 18.87 & 21.99 \\
1 & $0.5 \%$ & 13.15 & 15.34 & 3.97 & 10.82 \\
2 & $1.0 \%$ & 19.52 & 27.02 & 19.62 & 22.05 \\
3 & $5.0 \%$ & 12.31 & 23.82 & 23.61 & 19.91 \\
4 & $0.5 \%$ & 26.66 & 25.6 & 24.16 & 25.47 \\
5 & $1.0 \%$ & 30.55 & 23.09 & 27.4 & 27.01 \\
6 & $5.0 \%$ & 32.11 & 29.08 & 25.62 & 28.94 \\
7 & $0.5 \%$ & 27.8 & 31.21 & 28.36 & 29.12 \\
8 & $1.0 \%$ & 31.5 & 36.89 & 29.88 & 32.76 \\
9 & $5.0 \%$ & 30.19 & 33.1 & 31.37 & 31.55 \\
\hline
\end{tabular}




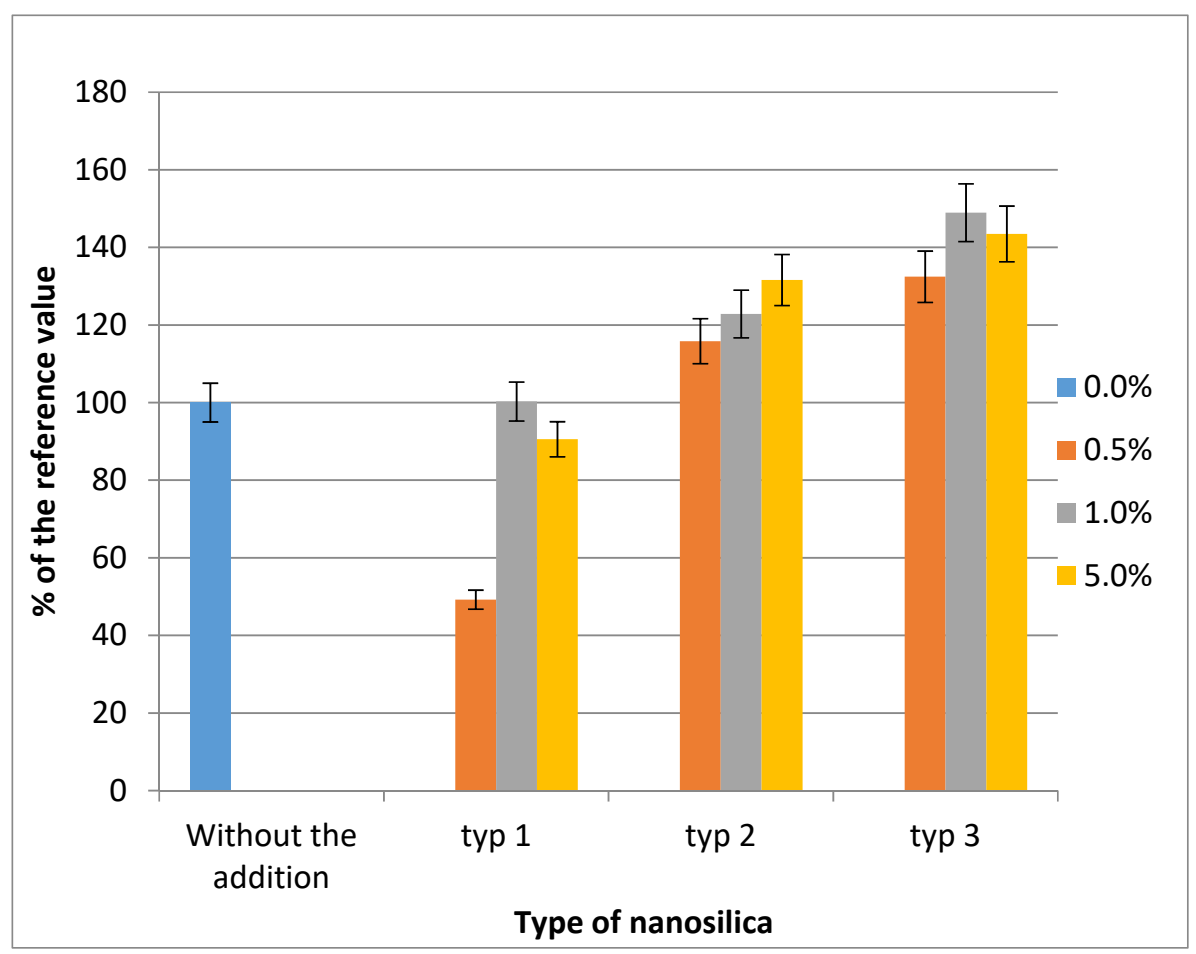

Figure 6. Compressive strength change in relation to the type and amount of nanosilica additive.

Table 3. Selected statistical parameters of the obtained results.

\begin{tabular}{|c|c|c|c|c|c|c|c|}
\hline $\begin{array}{l}\text { System } \\
\text { No. }\end{array}$ & $\begin{array}{l}\text { Max. } \\
(\mathrm{MPa})\end{array}$ & $\begin{array}{l}\text { Min. } \\
\text { (MPa) }\end{array}$ & Range (MPa) & $\begin{array}{c}\text { Range as } \% \text { of } \\
\text { the Mean } \\
\text { Value }(\%)\end{array}$ & $\begin{array}{l}\text { Standard } \\
\text { Deviation } \\
\text { (MPa) }\end{array}$ & $\begin{array}{l}\text { Standard Deviation } \\
\text { as } \% \text { of the Mean (\%) }\end{array}$ & $\begin{array}{c}\% \text { of the } \\
\text { Reference Value } \\
\text { (\%) }\end{array}$ \\
\hline 0 & 24.31 & 18.87 & 5.44 & 24.73 & 2.81 & 12.77 & 100.00 \\
\hline 1 & 15.34 & 3.97 & 11.37 & 105.08 & 6.03 & 55.75 & 49.20 \\
\hline 2 & 27.02 & 19.52 & 7.5 & 34.01 & 4.30 & 19.51 & 100.27 \\
\hline 3 & 23.82 & 12.31 & 11.51 & 57.80 & 6.59 & 33.07 & 90.54 \\
\hline 4 & 26.66 & 24.16 & 2.5 & 9.81 & 1.25 & 4.93 & 115.82 \\
\hline 5 & 30.55 & 23.09 & 7.46 & 27.62 & 3.75 & 13.86 & 122.83 \\
\hline 6 & 32.11 & 25.62 & 6.49 & 22.43 & 3.25 & 11.22 & 131.57 \\
\hline 7 & 31.21 & 27.8 & 3.41 & 11.71 & 1.83 & 6.28 & 132.42 \\
\hline 8 & 36.89 & 29.88 & 7.01 & 21.40 & 3.67 & 11.20 & 148.94 \\
\hline 9 & 33.1 & 30.19 & 2.91 & 9.22 & 1.46 & 4.64 & 143.47 \\
\hline
\end{tabular}

Table 4. Change in the strength of samples in relation to the unmodified sample.

\begin{tabular}{ccccccc}
\hline & No Add-on & Type 1 & Type 2 & Type 3 & $\begin{array}{c}\text { Average Value for the } \\
\text { Selected Concentration } \\
\text { (MPa) }\end{array}$ & $\begin{array}{c}\text { Average as } \\
\text { Reference (\%) }\end{array}$ \\
\hline $0.5 \%$ & - & 10.82 & 25.47 & 29.12 & 21.81 & 99.15 \\
$1.0 \%$ & - & 22.05 & 27.01 & 32.76 & 27.27 & 124.01 \\
$5.0 \%$ & - & 19.91 & 28.94 & 31.55 & - & - \\
$0 \%$ & - & - & - & - & - & - \\
Average for a given type (MPa) & - & 17.60 & 27.14 & 31.14 & - & - \\
Average as reference (\%) & - & 80.00 & 123.41 & 141.61 & & - \\
\hline
\end{tabular}

The article presents the effect of the size distribution of silica nanoparticles (types of nanosilica) and their concentration on the mechanical properties of cement slurry (compressive strength) matured under elevated temperature conditions. Compressive strength was chosen as the evaluation parameter. This parameter is the most basic criterion and is crucial for the further drilling of the hole. It is also very important due to the universality of the research method, as well as its connection with structural parameters. The 
initial hypothesis of the research undertaken assumed the improvement of the strength of samples containing nanosilica, due to the several times' greater specific surface of these nanoparticles. Analyzing the results (Table 4), it can stated that the highest percentage increase in compressive strength (on average by $41.6 \%$ ) was obtained for type 3 nanosilica with different particle sizes. All types of nanoparticles had the same order of diameters, but the specific surface area varied considerably due to the differences in the particle size distribution. Improvement in strength occurs in the case of slurries with the addition of type 2 nanosilica (on average by $23.4 \%$ ). However, the strength increase in relation to the reference cement slurry was lower than that of the slurries with the addition of type 3 nanosilica. In the case of type 1 nanosilica addition, the lack of strength increase of the samples was related to their uneven distribution in the cement matrix. This problem also applied to higher concentrations (5\%) for type 3 nanosilica. Then the high surface energy contributed to the agglomeration of particles and, due to the too high water demand of nanoparticles, it was problematic to mix the cement even in the initial period. Probably the increase in the concentration of the superplasticizer allowed for a more even distribution of $\mathrm{SiO} 2$ nanoparticles in the cement slurry, even with their high content.

Cement slurries with the addition of type 1 nanosilica were the most diverse in terms of strength. In all cases, they showed the greatest difference between the extreme values (range). In the case of $0.5 \%$ concentration, the range value was as much as $105 \%$ of the mean value, and the standard deviation was $55.75 \%$ of the mean. This was due to the much lower strength of one of the samples due to its defect. However, due to the small sample size, it was not decided to reject it earlier. For the concentration of $1 \%$ and $5 \%$ of nanosilica of this type, the range value was also relatively high, $34.01 \%$ and $57.8 \%$, respectively (standard deviations of $19.51 \%$ and $33.07 \%$ of the mean, respectively). This proves the high heterogeneity in terms of strength. For cement slurries with type 2 nanosilica admixture, the strength measurements were more homogeneous. For increasing concentrations, the range was $9.81 \%, 27.62 \%$ and $22.43 \%$ of the mean, respectively, which translates into a smaller standard deviation of $4.93 \%, 13.86 \%$ and $11.22 \%$ of the mean. The most homogeneous results of strength measurements were observed for cement slurries with an admixture of type 3 nanosilica. They present the smallest stretch marks and deviations from the average. The range was $11.71 \%, 21.4 \%$ and $9.22 \%$ of the mean, respectively, while the standard deviation was $6.28 \%, 11.2 \%$ and $4.64 \%$ of the mean. This indicates the group of results most concentrated around the mean. In all three cases there was an increasing trend, i.e., an increase in strength along with an increase in nanosilica content. The analysis of the linear correlation for all three types of admixture shows the greatest dependence for type 2 (Pearson correlation coefficient 0.94 , coefficient $R^{2}=0.8771$. In other cases the linear correlation was not very clear (for type 1 admixture: Pearson coefficient equal to $0,43, R^{2}=0.1851$ ) or basically did not occur (for type 3 admixture, Pearson's coefficient was at the level of $0.29, R^{2}=0.084$ ). On this basis, it can be concluded that the relationship between the content of the admixture and the increase in strength for groups 1 and 3 is nonlinear (Figures 7-9).

Comparing the obtained results for individual concentrations, it can be stated that the highest average increase in strength occurred for the sample with the addition of $1 \%$ nanosilica. This amount caused the greatest increase in strength with no significant deterioration in rheological parameters.

The mechanism responsible for improving the compactness of the microstructure and increasing the strength of cement stones can be presented as follows. When small amounts of nanoparticles are well dispersed in the cement slurry, the cement hydration products begin to deposit on the nanoparticles due to their high surface energy, and during hydration, begin to grow into conglomerates containing nanoparticles as nuclei. The nanoparticles located in the cement slurry will additionally support and accelerate cement hydration due to their high reactivity. This is due to the pozzolanic reaction in the cement and the effect of filling the pores, as a result of which the porosity of the cement system decreased. The use of colloidal silica accelerates the dissolution of $\mathrm{C}_{3} \mathrm{~S}$ and the rapid 
formation of the CSH phase in the cement slurry, and prevents the formation of large crystals, such as $\mathrm{Ca}(\mathrm{OH})_{2}$. By achieving an even dispersion of nanoparticles, it is possible to obtain an appropriate microstructure with good dispersed conglomerates characterized by high mechanical strength.

The addition of silica nanoparticles affects the morphology and mineralogy of hydration products and the rate of their formation. The additional amount of CSH gel formed and the density of the structure is a key factor for which the slurry strength and durability depend. Taking all this into account, it can be confirmed with certainty that nanosilica particles can effectively increase the compressive strength of class $G$ cement deposited in the oilwell.

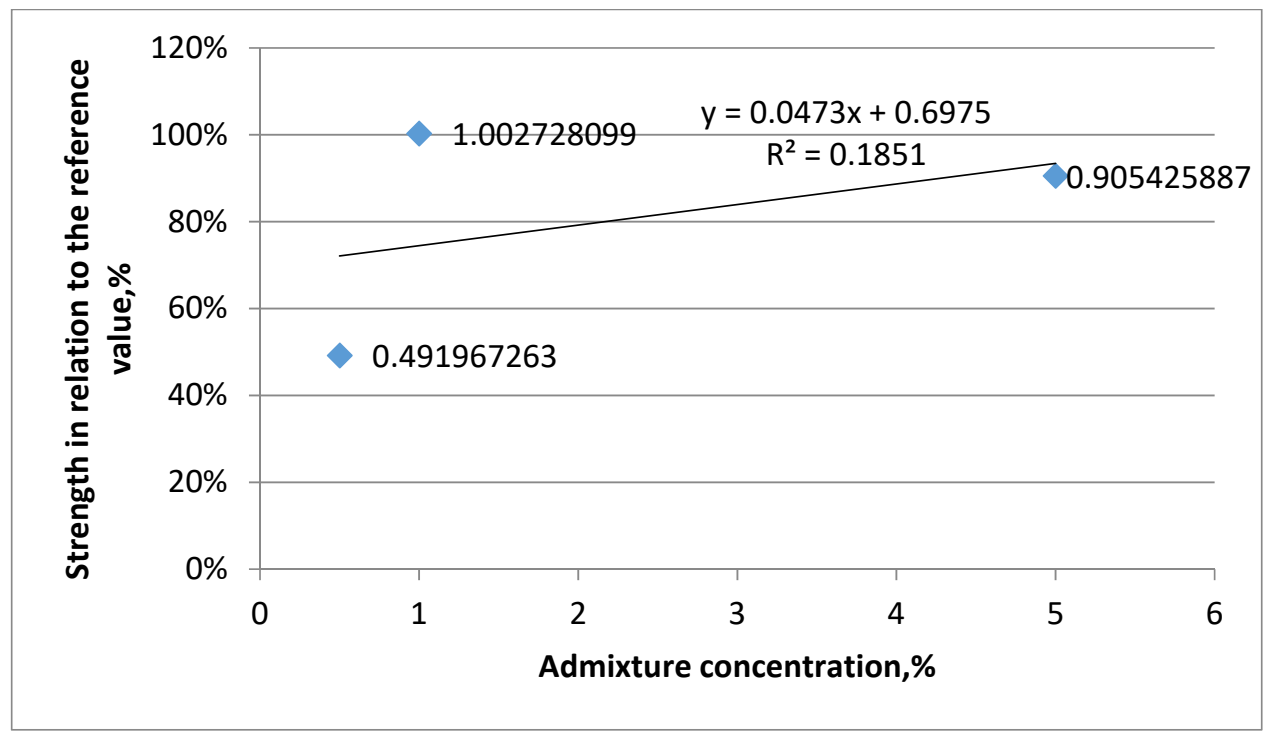

Figure 7. Compressive strength change depending on the type and amount of nanosilica additivecorrelation analysis for cement slurry with nanosilica type 1 .

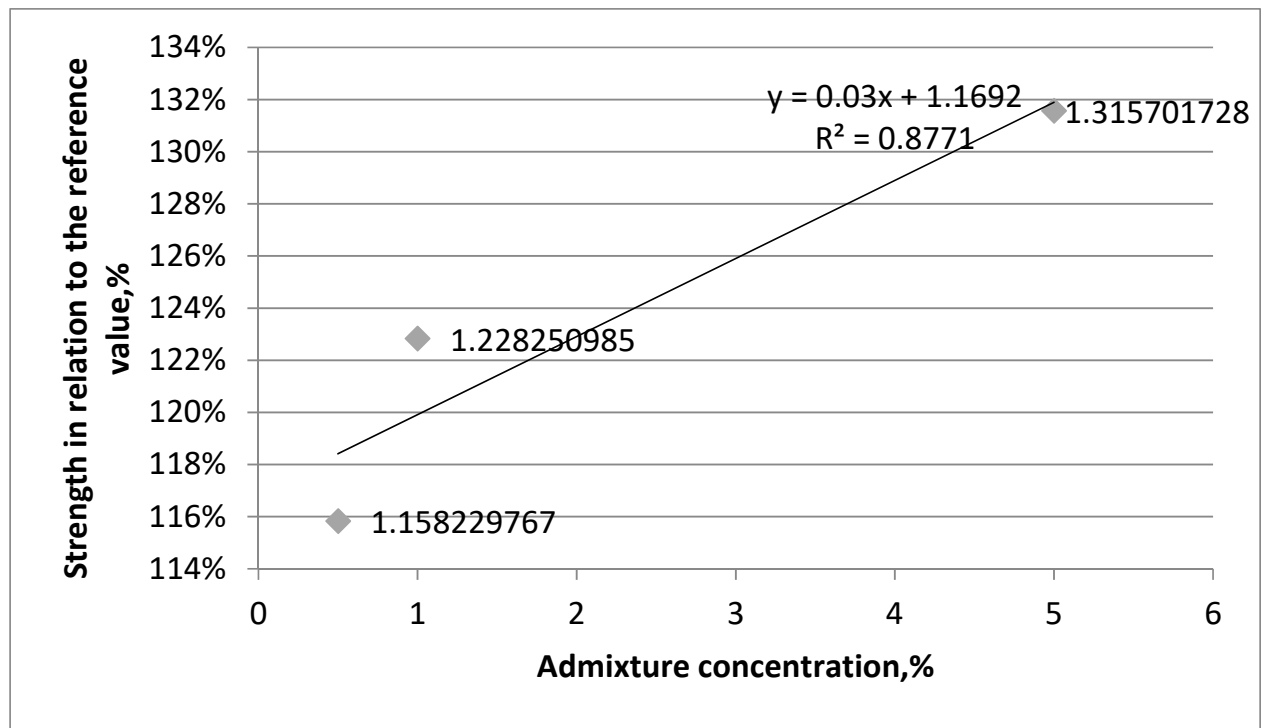

Figure 8. Compressive strength change depending on the type and amount of nanosilica additivecorrelation analysis for cement slurry with nanosilica type 2 . 


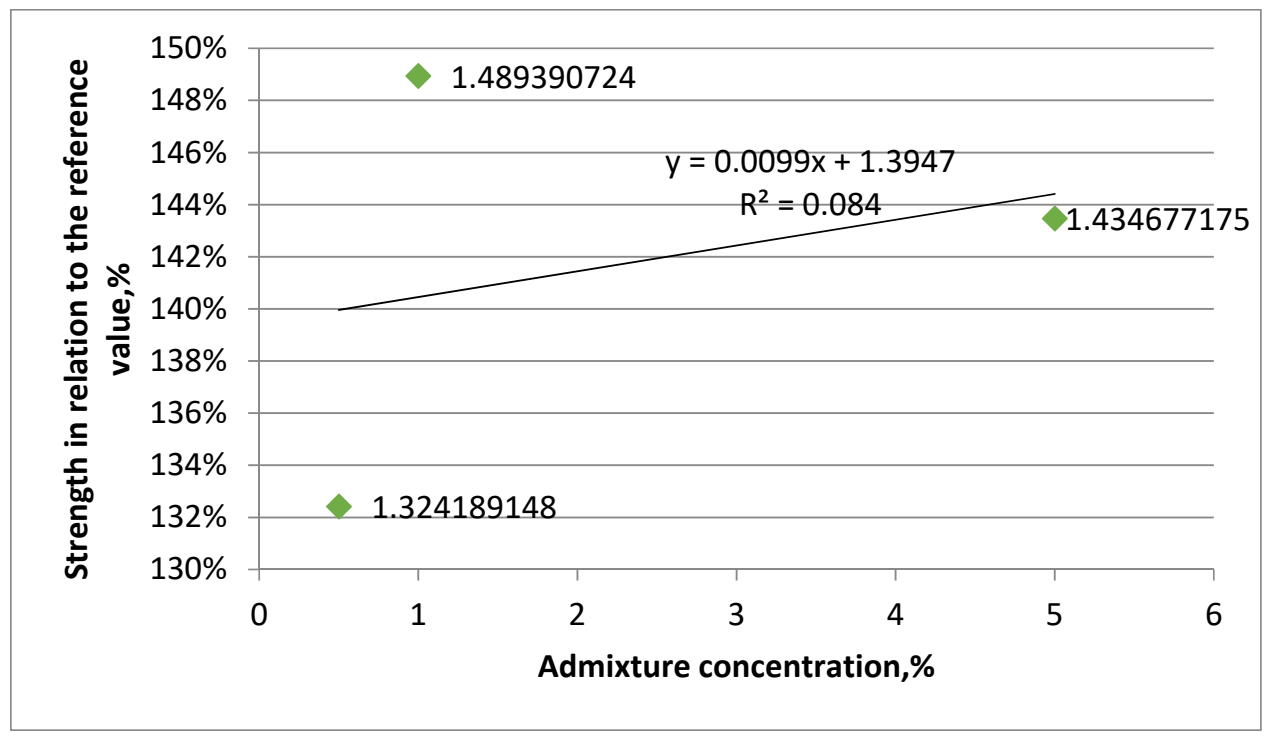

Figure 9. Compressive strength change depending on the type and amount of nanosilica additivecorrelation analysis for cement slurry with nanosilica type 3 .

\section{Conclusions}

- The addition of each of the tested types of nanosilica increases the strength, but the increase is different due to the type and concentration of the admixture.

- Type 1 nanosilica admixture causes the smallest increase in strength. This can be explained by the uneven dispersion of the admixture in the cement matrix. There is no linear relationship between the increase in strength and the increasing concentration of nanosilica.

- The admixture of type 2 nanosilica causes a greater increase in strength than type 1 , it also has a smaller scatter of results and shows a linear trend between the increase in strength and the increase in concentration.

- Type 3 nanosilica admixture causes the greatest increase in strength, as evidenced by the highest values and the smallest dispersion. It may be the result of a tighter filling of the cement matrix with particles with the smallest and most diverse particles. There is no linear dependence of the increase in strength on the increasing concentration of this type of nanosilica.

- The concentration of $0.5 \%$, a fairly low concentration, resulted in the slightest increase in strength, in one case this increase is even less noticeable due to a defective sample.

- For the concentration of $1 \%$, the addition of nanosilica in such an amount caused the greatest increase in strength and small scatter of results probably due to good dispersion in the cement matrix.

- The concentration of $5 \%$, a relatively high concentration, resulted in a noticeable increase in strength, but it was also the cause of difficulties in the dispersion of nanosilica particles in the cement matrix.

On the basis of the obtained results, we conclude that the optimal amount of nanosilica is a concentration equal to $1 \%$ (bwoc). Cement stone modified with the addition of nanosilica shows an improvement in mechanical properties, which is manifested by an increase in compressive strength. However, the underlying problem is the difficulty in properly dispersing the nanoparticles. The next step to confirm the positive effect of nanosilica is the study of the microstructure and permeability of cement stone carried out in order to visualize the condition of the cement matrix of slurries modified with the addition of nanosilica deposited in a borehole-like environment. 
Author Contributions: Methodology, A.P.; software, M.K.; formal analysis, A.P. and J.Z.; data curation, A.P. and M.K.; writing—original draft preparation, A.P.; writing—review and editing, J.Z. and M.K.; visualization, J.Z.; project administration, J.Z.; funding acquisition, A.P. and J.Z. All authors have read and agreed to the published version of the manuscript.

Funding: The work was financially supported by Ministry of Science and Higher Education Warsaw (Internal order Oil and Gas Institute-National Research Institute Project No. 0015/KW/21) and by AGH-UST in Kraków-Faculty of Drilling, Oil and Gas, Drilling and Geoengineering Department, project No. 16.16.190.779.

Institutional Review Board Statement: Not applicable.

Informed Consent Statement: Not applicable.

Data Availability Statement: Not applicable.

Acknowledgments: The author thanks the anonymous reviewers for their constructive comments and the editor for handling the paper.

Conflicts of Interest: The author declares no conflict of interest.

\section{References}

1. Shadravan, A.; Amani, M. HPHT 101-What Every Engineer or Geoscientist Should Know about High Pressure High Temperature Wells. Presented at the SPE Kuwait International Petroleum Conference and Exhibition, Kuwait City, Kuwait, 10 December 2012 [CrossRef]

2. El-Gamal, S.M.; Hashem, F.S.; Amin, M.S. Influence of carbon nanotubes, nanosilica and nanometakaolin on some morphologicalmechanical properties of oil well cement pastes subjected to elevated water curing temperature and regular room air curing temperature. Constr. Build. Mater. 2017, 146, 531-546. [CrossRef]

3. Murtaza, M.; Rahman, M.K.; Al-Majed, A.A. Effect of Nanoclay on Mechanical and Rheological Properties of Oil Well Cement Slurry under HPHT Environment. Presented at the International Petroleum Technology Conference, Bangkok, Thailand, 12 November 2016. [CrossRef]

4. Li, L.; Yuan, X.; Xu, X.; Li, S.; Wang, L. Vital Role of Nanotechnology and Nanomaterials in the Field of Oilfield Chemistry. Presented at the International Petroleum Technology Conference, Beijing, China, 26 March 2013. [CrossRef]

5. Hoelscher, K.P.; Young, S.; Friedheim, J.; De Stefano, G. Nanotechnology Application in Drilling Fluids. Presented at the Offshore Mediterranean Conference and Exhibition, Ravenna, Italy, 13 March 2013.

6. Kong, X.; Ohadi, M.M. Applications of Micro and Nano Technologies in the Oil and Gas Industry-An Overview of the Recent Progress. Presented at the Abu Dhabi International Petroleum Exhibition and Conference, Abu Dhabi, United Arab Emirates, 1 November 2010. [CrossRef]

7. Patil, R.; Deshpande, A. Use of Nanomaterials in Cementing Applications. Presented at the SPE International Oilfield Nanotechnology Conference and Exhibition, Noordwijk, The Netherlands, 12 June 2012. [CrossRef]

8. Khalil, M.; Jan, B.M.; Tong, C.W.; Berawi, M.A. Advanced nanomaterials in oil and gas industry: Design, application and challenges. Appl. Energy 2017, 191, 287-310. [CrossRef]

9. Mohammed, A.S. Vipulanandan models to predict the electrical resistivity, rheological properties and compressive stress-strain behavior of oil well cementmodified with silica nanoparticles. Egypt. J. Pet. 2018, 27, 1265-1273. [CrossRef]

10. Fakoya, M.F.; Shah, S.N. Emergence of nanotechnology in the oil and gas industry: Emphasis on the application of silica nanoparticles. Petroleum 2017, 3, 391-405. [CrossRef]

11. Dębińska, E. Niekonwencjonalne zaczyny cementowe z dodatkiem nanokrzemionki. Nafta-Gaz 2015, 5, 290-300.

12. Vryzas, Z.; Mahmoud, O.; Nasr-El-Din, H.A.; Kelessidis, V.C. Development and Testing of Novel Drilling Fluids Using $\mathrm{Fe}_{2} \mathrm{O}_{3}$ and $\mathrm{SiO}_{2}$ Nanoparticles for Enhanced Drilling Operations. Presented at the International Petroleum Technology Conference, Doha, Qatar, 6 December 2015. [CrossRef]

13. Cocuzza, M.; Pirri, F.; Rocca, V.; Verga, F. Is the Oil Industry Ready For Nanotechnologies? Presented at the Offshore Mediterranean Conference and Exhibition, Ravenna, Italy, 23-25 March 2011.

14. Gibson, S. Novel Solution to Cement Strength Retrogression. Presented at the SPE/IADC Drilling Conference and Exhibition, Amsterdam, The Netherlands, 1 March 2011. [CrossRef]

15. Murtaza, M.; Rahman, M.K.; Al-Majed, A.A.; Samad, A. Mechanical, Rheological and Microstructural Properties of Saudi Type G Cement Slurry with Silica Flour Used in Saudi Oil Field under HTHP Conditions. Presented at the SPE Saudi Arabia Section Technical Symposium and Exhibition, Al-Khobar, Saudi Arabia, 19 May 2013. [CrossRef]

16. Santra, A.; Boul, P.J.; Pang, X. Influence of Nanomaterials in Oilwell Cement Hydration and Mechanical Properties. Presented at the SPE International Oilfield Nanotechnology Conference and Exhibition, Noordwijk, The Netherlands, 12 June 2012. [CrossRef]

17. Kim, J.J.; Rahman, M.K.; Al-Majed, A.A.; Al-Zahrani, M.M.; Taha, M.M. Nanosilica effects on composition and silicate polymerization in hardened cement paste cured under high temperature and pressure. Cem. Concr. Compos. 2013, 43, 78-85. [CrossRef] 
18. Singh, L.P.; Zhu, W.; Howind, T.; Sharma, U. Quantification and characterization of C-S-H in silica nanoparticles incorporated cementitious system. Cem. Concr. Compos. 2017, 79, 106-116. [CrossRef]

19. Constantinides, G. Nanoscience and nanoengineering of cement-based materials. In Nanotechnology in Eco-Efficient Construction; Woodhead Publishing: Sawston, UK, 2013. [CrossRef]

20. Yuan, B.; Wang, Y.; Yang, Y.; Xie, Y.; Li, Y. Wellbore sealing integrity of nanosilica-latex modified cement in natural gas reservoirs with high H2S contents. Constr. Build. Mater. 2018, 192, 621-632.

21. Dębińska, E. Wpływ nanotlenków glinu i cynku na parametry świeżego i stwardniałego zaczynu cementowego. Nafta-Gaz 2016, 4, 251-261. [CrossRef]

22. Chartier, M.A.; Thompson, S.; Bordieanu, M.; Bustamante, G.; Saunders, J.R.; Kaiser, T.M. Performance Characterization and Optimization of Cement Systems for Thermally Stimulated Wells. Presented at the SPE Canada Heavy Oil Technical Conference, Calgary, AB, Canada, 9 June 2015. [CrossRef]

23. Saebom, K.; Chun, H. Use of nanoparticles for oil production applications. J. Pet. Sci. Eng. 2019, 172, 97-114.

24. Lau, H.C.; Yu, M.; Nguyen, Q.P. Nanotechnology for Oilfield Applications: Challenges and Impact. Presented at the Abu Dhabi International Petroleum Exhibition \& Conference, Abu Dhabi, United Arab Emirates, 7 November 2016. [CrossRef]

25. Lau, H.C.; Yu, M.; Nguyen, Q.P. Nanotechnology for oilfield applications: Challenges and impact. J. Pet. Sci. Eng. 2017, 157, 1160-1169. [CrossRef]

26. Wang, C.; Chen, X.; Wei, X.; Wang, R. Can nanosilica sol prevent oil well cement from strength retrogression under high temperature? Constr. Build. Mater. 2017, 144, 574-585. [CrossRef]

27. Ghoddousi, P.; Javid, A.A.; Zareechian, M. Physical and chemical effects of siliceous particles at nano, micro, and macro scales on properties of self-consolidating mortar overlays. Constr. Build. Mater. 2018, 189, 1140-1154. [CrossRef]

28. Murtaza, M.; Mahmoud, M.; Elkatatny, S.; Majed, A.A.; Chen, W.; Jamaluddin, A. Experimental Investigation of the Impact of Modified Nano Clay on the Rheology of Oil Well Cement Slurry. Presented at the International Petroleum Technology Conference, Beijing, China, 22 March 2019. [CrossRef]

29. Qalandari, R.; Aghajanpour, A.; Khatibi, S. A Novel Nanosilica-Based Solution for Enhancing Mechanical and Rheological Properties of Oil Well Cement. Presented at the SPE Asia Pacific Oil and Gas Conference and Exhibition, Brisbane, Australia, 23 October 2018. [CrossRef]

30. Friedheim, J.; Young, S.; De Stefano, G.; Lee, J.; Guo, Q. Nanotechnology for Oilfield Applications—Hype or Reality? Presented at the SPE International Oilfield Nanotechnology Conference and Exhibition, Noordwijk, The Netherlands, 12 June 2012. [CrossRef]

31. Horszczaruk, E.; Mijowska, E.; Cendrowski, K.; Mijowska, S.; Sikora, P. The influence of nanosilica with different morphology on the mechanical properties of cement mortars. Cem. Wapno Beton 2013, 18, 24-32.

32. Luo, Z.; Li, W.; Wang, K.; Shah, S.P. Research progress in advanced nanomechanical characterization of cement based materials. Cem. Concr. Compos. 2018, 94, 277-295.

33. Bera, A.; Belhaj, H. Application of nanotechnology by means of nanoparticles and nanodispersions in oil recovery-A comprehensive review. J. Nat. Gas Sci. Eng. 2016, 34, 1284-1309.

34. Mahmoud, A.A.; Elkatatny, S.; Mahmoud, M. Improving Class G Cement Carbonation Resistance Using Nanoclay Particles for Geologic Carbon Sequestration Applications. Presented at the Abu Dhabi International Petroleum Exhibition \& Conference, Abu Dhabi, United Arab Emirates, 12 November 2018. [CrossRef]

35. Murtaza, M.; Rahman, M.K.; Al Majed, A.A.; Tariq, Z.; Mahmoud, M. Scratch Test for Strength and Toughness of Oil Well Cement with Nanoclay as an Additive. Presented at the Abu Dhabi International Petroleum Exhibition \& Conference, Abu Dhabi, United Arab Emirates, 11 November 2019. [CrossRef] 